\title{
Sonochemical Synthesis of Amorphous Zinc Phosphate Nanospheres
}

\author{
Seung-Ho Jung, Eugene Oh, Daeseob Shim, Da-Hye Park, Seungho Cho, Bo Ram Lee, Yeon Uk Jeong, ${ }^{\dagger}$ \\ Kun-Hong Lee, and Soo-Hwan Jeong.t* \\ Department of Chemical Engineering, Pohang Linwersity of Science and Technology, Pohang 790-784, Korea \\ ${ }^{*}$ E-mail: ce200t7iapostech ack ${ }^{4}$ \\ School of Materials Science and Engineering. Kungpook National Cniversity, Daegu 702-701. Korea \\ -Department of Chemical Engineering. Kutmgpook Kational Lniversitv, Daegu 702-701, Korea \\ E-mail: shjeongiâkmiac.hr \\ Recerved April 15, 2009, Accepted August 18, 2009
}

\begin{abstract}
Amorphous zinc phosphate nanospheres were prepared wia a sonochemical route. Zinc phosphate nanospheres were unifonm in shape with an average diameter of $210 \mathrm{~nm}$. The average diameter of nanospheres could be controlled by changing the $\mathrm{pH}$ of a precursor solution. This sonochemical method is simple, facile, economical, and environmentally benign. Non-crystalline characteristics of as-prepared zinc phosphate nanospheres were confimed by X-ray diffraction, transmission electron microscopy, and FT-IR spectroscopy analyses. We believe this technique will be readily adopted in realizing other forms of zinc phosphate nanostructures.
\end{abstract}

Key Words: Zinc phosphate, Nanosphere, Ultrasound, Sonochemistry

\section{Introduction}

The design of nanostructured materials with various shapes has given an impetus to the development of nanoscience and nanotechnology as a key factor in tailoring the plysical and chemical properties of nanostructures..$^{1-4}$ Thus the shape control of various nanostructured materials has attracted great attention in recent materials chemistry. Zinc phosphate $\left(Z \mathrm{n}_{3}\right.$ $\left.\left(\mathrm{PO}_{4}\right)_{2}\right)$ is one of the most important multifunctional materials for potential applications. including environmentally friendly anticorrosive pigments and dental cements due to its low solubility in water/biological environment and biocompatibility. ${ }^{5.6}$ In addition, the cataly tic properties of zinc phosphate have been investigated in hydrocarbon conversion process. such as dehy'dration/dehy'drogenation of sec-butanol and methanol conversion. ${ }^{7}$

Since the first report on the synthesis of microporous zinc phosphates. ${ }^{9}$ various techniques. including a solid-state reaction ${ }^{11}$ and a polyol-mediated approach ${ }^{13}$ have been investigated for the synthesis of monodispersed and nonagglomerated zinc phosphate nanoparticles. A solid-state reaction is a simple room temperature process. but it requires very long reaction time (from several hours to several days) for the fabrication of zine phosphate nanoparticles. ${ }^{10,12}$ Unlike the solid-state reaction. a polyol-mediated approach is a relatively fast route (up to several hours) to the preparation of nonagglomerated zinc phosphate nanoparticles. ${ }^{11.13 .14}$ However. the polyol-mediated approach requires both a heating system due to the relatively high temperature process (up to $300{ }^{\circ} \mathrm{C}$ ) and an additional cooling system for refluxing process.

Therefore, the development of a simple and fast route to the growth of zinc phosphate nanostructured materials with various shapes under ambient conditions has remained an important topic of investigation. In recent y'ears. a sonochemical technique has been developed as a promising alternative technique for the synthesis of morphology-controlled inorganic nanostnuctured materials. ${ }^{4.15 .1}$ ? The reason is that this sonochemical technique is a fast. simple. convenient. economical, and environmentally benign process. ${ }^{18-3)}$ Herein. we report on the selective sy nthesis of amorphous zinc phosphate nanospheres via a facile sonochemical route.

\section{Experimental Section}

Amorphous zinc phosphate nanospheres were fabricated in a horn-type reaction vessel using an ultrasonic technique. Zinc phosphate tetrahydrate $\left(\mathrm{Zn}_{3}\left(\mathrm{PO}_{4}\right)_{2} \cdot 4 \mathrm{H}_{2} \mathrm{O} .98 \%\right.$. Junsei) were used as a precursor chemical. For the production of zinc phosphate nanospheres, $0.4582 \mathrm{~g}$ zinc phosphate tetralydrate was dissolved in a mixture of $15 \mathrm{~mL}$ ammonia water (28 30 wt\%. Kanto) and $85 \mathrm{~mL}$ distilled (DI) water at room temperature. Concentrations of zinc phosphate and ammonia were 0.01 and $2.36 \mathrm{M}$, respectively. The $\mathrm{pH}$ of the precursor solution was 12.3 . Ultrasonic wave was introduced at an intensity of $39.5 \mathrm{~W} / \mathrm{cm}^{2}$ for $30 \mathrm{~min}$ by a sonochemical apparatus (frequency of $20 \mathrm{kHz}$ ) under ambient conditions. in order to synthesize amorphous zinc phosphate nanospheres. The zinc phosphate nanosphere-containing solution was filtered with a polycarbonate membrane that had pores of 100 $\mathrm{nm}$ in diameter. Zinc phosphate nanospheres were washed with DI water after filtration. and then dried in an oven.

The volumetric ratio between ammonia water and DI water in $100 \mathrm{~mL}$ precursor solution was changed for the diameter control of zinc phosphate nanospheres. For large-diametered zinc phosphate nanospheres. the concentration of ammonia was increased to $3.14 \mathrm{M}(20 \mathrm{~mL}$ ammonia water with $80 \mathrm{~mL}$ DI water) and $4.71 \mathrm{M} \mathrm{(30} \mathrm{mL}$ ammonia water with $70 \mathrm{~mL}$ DI water). The $\mathrm{pH}$ of the precursor solution was 12.5 and 12.8 at $3.1+$ and $4.71 \mathrm{M}$ ammonia concentration. respectively. Except for the difference in ammonia concentration of precursor 
solutions, the concentration level of zinc phosphate, an intensity of ultrasonic wave. and reaction time were fixed at $0.01 \mathrm{M} .39 .5 \mathrm{~W} / \mathrm{cm}^{-}$, and $30 \mathrm{~min}$. respectively.

The morphology of as-prepared zinc phosphate nanospheres was observed by field emission scanning electron microscope (FESEM, Hitachi S-4300SE). The crystallinity. crystal stricture and chemical composition were characterized by transmission electron microscope (TEM. JEOL JEM-2010), $\mathrm{X}$-ray diffraction (XRD. Max Science. M18XHF). energy-dispersive X-ray (EDX) spectroscopy and Fourier Transform Infrared (FT-IR) spectroscopy.

\section{Results and Discussion}

Figure I shows FESEM images and diameter distribution of as-prepared zinc phosphate nanostructured materials via a sonochemical route. Zinc phosphate nanospheres with different diameters could be clearly observed in Figure 1(a)-(c). The average diameter increased from 210 to $1000 \mathrm{~nm}$ as the ammona concentration in precursor solution increased from 2.36 (15 mL in volume, $\mathrm{pH}=12.3)$ to $4.71 \mathrm{M}(30 \mathrm{~mL}$ in volume, $\mathrm{pH}=12.8$ ). as shown in Figure 1(d). At low ammonia concentration of $2.36 \mathrm{M}$, the standard deviation in diameter was as small as $70 \mathrm{~nm}$. On the contrary the standard deviation in diameter was as large as $360 \mathrm{~nm}$ at high ammona concentration of $4.71 \mathrm{M}$. The Ostwald ripening phenomenon is known as a key factor which cause the diameter distribution of nanoparticles by the solubility difference due to size-induced energetic stability. $^{21 \text { ta }}$ Based on Ostwald ripening process. the larger particles continue to grow. whle smaller particles continue to shrink. It is thought that. as the ammonia concentration in precursor solution increased from 2.36 to $4.71 \mathrm{M}$, the Ostwald
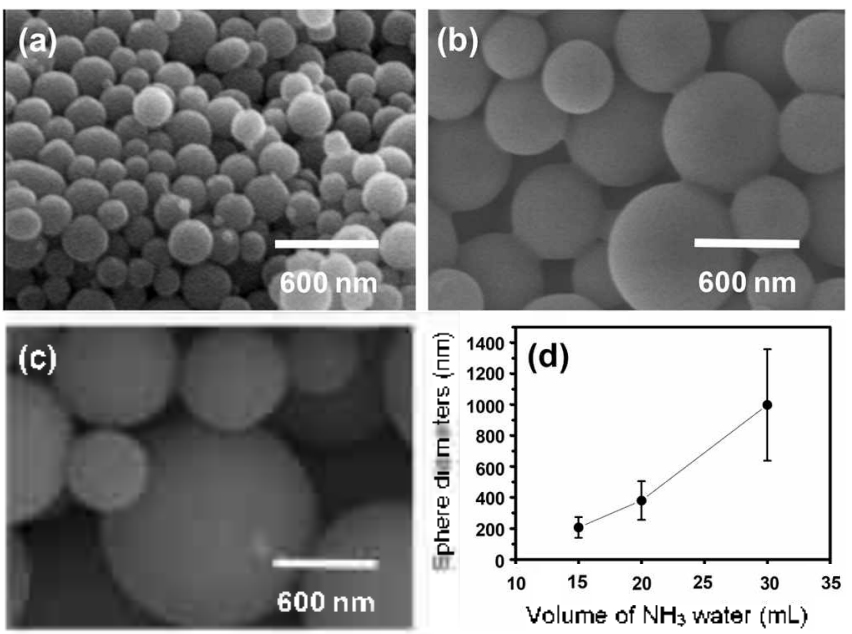

Figure 1. SEM images of amorphous zmc phosphate nanospheres synthesized at (a) $15 \mathrm{~mL}$ ammonia/85 $\mathrm{mL}$ DI ( $2.36 \mathrm{M}$ ammonia), (b) $20 \mathrm{~mL}$ ammonia/ $80 \mathrm{~mL}$ DI (3.14 M ammonia), and (c) $30 \mathrm{~mL}$ ammonia/70 $\mathrm{mL}$ DI (4.71 M ammonia) aqueous solutions. The concentration level of zinc phosphate, an intensity of ultrasonic wave, and reaction time were fixed at $0.01 \mathrm{M}, 39.5 \mathrm{~W} / \mathrm{cm}^{2}$, and $30 \mathrm{~min}$, respectively. (d) Changes in diameter of amorphous zinc phosphate nanospheres as a function of the volume of ammonia water used in precursor solutions. Closed circles represent average diameters, and standard deviation is shown as error bars. nipening phenomenon became enhanced due to the increase in the amount of excessive hydroxyl ions $\left(\mathrm{OH}^{-}\right.$ions) which can dissolve zinc phosphate nanospheres. When ammonia water is used as hydroxide anion source material, large amount of growth units can be generated. Thus. isotropic growth from center nuclei can be mainly proceeded to form sphere-like zinc phosphate nanostructures.

The growth mechanism of zinc phosphate nanospheres was considered as follows:

$$
\begin{aligned}
& \mathrm{NH}_{3}+\mathrm{H}_{2} \mathrm{O} \longrightarrow \mathrm{NH}_{4}^{-}+\mathrm{OH}^{-} \\
& \mathrm{Zn}_{3}\left(\mathrm{PO}_{4}\right)_{2}+\mathrm{H}_{2} \mathrm{O}+4 \mathrm{OH}^{-} \longrightarrow \\
& \quad 2 \mathrm{Zn}^{2-}+2 \mathrm{PO}_{4}^{3-}+\mathrm{Zn}(\mathrm{OH})_{4}{ }^{3-}+4 \mathrm{H}_{2} \mathrm{O} \\
& 3 \mathrm{Zn}^{2-}+2 \mathrm{PO}_{4}^{3-} \stackrel{\mathrm{3})}{\longrightarrow} \mathrm{Zn}_{2}\left(\mathrm{PO}_{4}\right)_{2} \\
& 3 \mathrm{Zn}(\mathrm{OH})_{4}^{{ }^{2-}}+2 \mathrm{PO}_{4}^{3-} \stackrel{\mathrm{M})}{\longrightarrow} \mathrm{Zn}_{3}\left(\mathrm{PO}_{4}\right)_{2}+12 \mathrm{OH}^{-}
\end{aligned}
$$

where the symbol )) denotes ultrasonic irradiation.

Figure 2 shows the XRD pattern of zinc phosplate nanospheres shown in Figure I(a). Since there was no diffraction peaks observed from crystalline structures or other impurities, it is noted that pure amorphous zinc phosphate nanospheres were synthesized under the current sonochemical approach. This is consistent with the results of the TEM and electron diffraction pattern analyses as shown in the inset of Figure 2. The TEM (left inset in Figure 2) and the electron diffraction pattern (right inset in Figure 2) give the evidence again that as-prepared zinc phosphate nanospheres are noncrystalline. Because of their noncrystalline characteristic. quantitative and qualitative analyses were additionally conducted by EDX and FT-IR spectroscopies, respectively, in order to investigate the chemical composition of as-prepared zinc phosphate nanospheres.

EDX analy sis confinmed that as-prepared nanospheres were composed of $\mathrm{Zn}$. P. and $\mathrm{O}$ components only. The atonic ratio

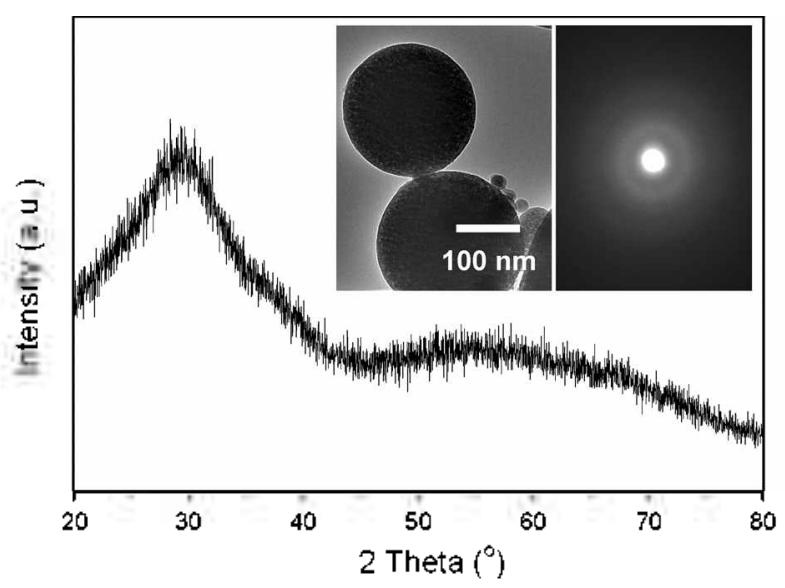

Figure 2. A XRD graph of the zinc phosphate nanospheres synthesized at $2.36 \mathrm{M}$ ammonia aqueous solution. Left and right insets are a TEM image and electron diffraction pattern of an individual nanosphere, respectively: 


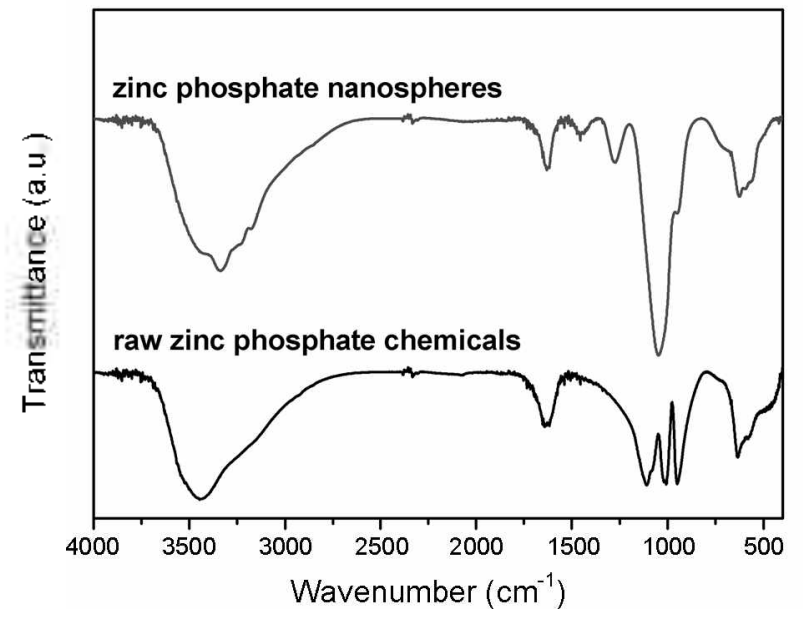

Figure 3. FT-IR spectra of amorphous zinc phosphate nanospheres (upper line) and raw zinc phosphate tetrahydrate chemicals (lower line ).

of $\mathrm{Zn} / \mathrm{P}$ was about 3/2, which corresponds with the $\mathrm{Zn}_{3}\left(\mathrm{PO}_{4}\right)_{2}$. The upper line in Figure 3 shows the FT-IR spectrum of as-prepared nanospheres. In order to verify that our as-synthesized nanospheres were zinc phosphate. the FT-IR analy sis was also conducted using typical zinc phosphate chemicals (zinc phosphate tetrahydrate) as a reference (lower line in Figure 3 ). The broad bands centered at $3347 \mathrm{~cm}^{-1}$ (ref: $3443 \mathrm{~cm}^{-1}$ ) is ascribed to the $\mathrm{O}-\mathrm{H}$ stretching vibration. In addition. the strong vibrational band at $1632 \mathrm{~cm}^{-1}$ was attributed to $\mathrm{H}_{2} \mathrm{O}$ bonding. It is noted that as-prepared zinc phosphate nanospheres are forms of hydrate.

The FT-IR spectra shows characteristic bands related to $\mathrm{PO}_{4}{ }^{3-}$ and $\mathrm{H}_{2} \mathrm{O}$. The broad bands shown at $400 \sim 700 \mathrm{~cm}^{-1}$ (peak at $630 \mathrm{~cm}^{-1}$ ) and $900 \sim 1300 \mathrm{~cm}^{-1}$ (ref: $900 \sim 1200 \mathrm{~cm}^{-1}$ ) were attributed to the bending and complex stretching vibrations of $\mathrm{PO}_{4}{ }^{3 \cdot}$ group. respectively. ${ }^{34}$ In the reference FT-IR spectnim. the vibrational bands split into three distinct peaks: $954 \mathrm{~cm}^{-1}, 1021 \mathrm{~cm}^{-1}, 1107 \mathrm{~cm}^{-1}$ due to $\mathrm{P}-\mathrm{O}$ bending, antisymmetric stretching of $\mathrm{PO}_{4}{ }^{3 .}$. and symmetric stretching of $\mathrm{PO}_{4}{ }^{3}$. respectively. ${ }^{10}$ The significant differences between the reference FT-IR spectrum and the FT-IR spectrum of as-prepared nanospheres are the chemical shift of peaks. relative peak intensity. and the overlap between peaks in the vibrational bands. In our zinc phosphate nanosphere sy'stem. a very strong peak at 1050 $\mathrm{cm}^{-1}$ was observed due to the antisymmetric stretching of $\mathrm{PO}_{4}{ }^{3 .}$ with a shoulder peak at $945 \mathrm{~cm}^{-1}$ originated from $\mathrm{P}-\mathrm{O}$ bending. A small peak at $1270 \mathrm{~cm}^{-1}$ originated from symmetric stretching of $\mathrm{PO}_{4}{ }^{3 .}$ was red-shifted from the reference peak. We believe that these significant differences were observed due to the cry stallographic difference between our noncry stalline zinc phosphate nanospheres and typical crystalline zinc phosphate chemicals.

\section{Conclusions}

We demonstrated a simple sonochemical route to the selective sy nthesis of amorphous zinc phosphate nanospheres under ambient conditions. The average diameter of amorphous nanospheres could be controlled from $210 \mathrm{~nm}$ to $1000 \mathrm{~nm}$. Ammonia concentration level in aqueous precursor solution was an important factor in the diameter control of zinc phosphate nanospheres. Based on fast. simple convenient. economical. and environmentally benign characteristics, we expect that this sonochemical technique can be very useful in seeking to design zinc phosphate nanostructures with various morphologies.

Aclonowledgments. This work was supported by both the National Center for Nanomaterials Technology (NCNT) of the Ministry of Conmerce. Industry. and Energy (MOCIE) and the second phase BK2I program of the Korean Ministry of Education. Science and Technology

\section{Refeiences}

1. Alivisatos, A. P. Science 1996, 271,933

2. Xia, Y.; Yang, P.; Sun, Y; Wu, Y.; Mavers, B.; Gates, B.; Yin, Y.; Kim, F: Yan, H. Adv Mater. 2003, 15, 353.

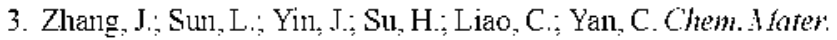
2002, 11,4172

4. Geng, J.; Lu, D.; Zhu, J.; Chen, H. J. Phys. Chent. B 2006, 110 , 13777.

5. Del Amo, B; Romagnoli, R; Vetere, V. F; Hemandez, L. S. Prog. Oig. Coat. 1998, 33, 28.

6. Czamecha, B.; Limanowska-Shaw, H.; Nicholson, I. W. $J$. Mater: Sci.: Mater. Med. 2003, 1\%,601.

7. Tada, A.; Itoh, H.; Kawasaki, Y; Nara, J. Chem. Lett. 1975, f, 517.

8. Tagiyev, D. B; Aliyev, A. M; Mamedov, N. D; Fatullayeva, S. S. Stud. Surf. Sci. Catal. 2004, 154, 1049

9. Gier, T. E.: Stucky, G. D. Nature 1991, 349, 508.

10. Ylan, A. Q.: Liao, S.; Tong, Zh. F.; Whl, T.; Hulang, Z. Y. Mater: Lett. $\mathbf{2 0 0 6}, 60,2110$

11. Roming, M.: Feldmann, C.: Avadhut, Y. S.; anf der Gunne, I. S. Chem. Hater: 2008, 20,5787

12. Yuan, A. Q.; Wu, I.; Huang, Z. Y.: Wu, K.: Liao, S.: Tong, Zh. F. Mater Res. Bull. 2008, $43,1339$.

13. Feldmann, C.: Jungk, H.-O. Angew. Chem. Int. Ed. 2001, 40, 359.

14. Dawood, F.; Leonard, B. M:; Schaak, R. E. Chem. Mater: 2007. 19,4545 .

15. Jung, S.-H.; Oh, E, Lee, K.-H.: Yang, Y.: Park, C. G.: Park, W.; Teong, S.-H. Cryst. Growth Des. $2008,8,265$.

16. Geng, J.: Zhu, J.-T; Chen, H.-Y. Cinst. Growth Des. 2006, 6 , 321 .

17. Xu, M.; Lu, Y.-N.: Liu, Y.-F.: Shi, S.-Z.: Fang. F. J. Am. Ceram. Soc. 2006, 89,3631

18. Suslick, K. S.: Fang, M: Hyeon, T. J. Am. Chem. Soc. 1996, 118, 11960.

19. Yll, T. C.: Yll, I: Ho, W.; Zhang. L. Chem. Comm. 2001, 1942.

20. Dhas, N. A.; Suslick, K. S. J. Am. Chem. Soc. 2005, 127, 2368.

21. Sun, Y.: Mayers, B.: Herricks, T.; Xia, Y. Nano Lett. 2003, 3 , 955.

22. Mantzaris, N. V. Chem. Eng. Sci. 2005, 60,4749.

23. Ogle, K.; Tomandl, A.; Meddahi, N.; Wolpers, M. Conros. Sci. 2004. 46.979 .

24. Pawlig, O.; Trettin, R. Akaten Res. Bull. 1999, 34, 1959. 